\title{
Dimensions of rationing: who should do what?
}

\author{
Rudolf Klein
}

This paper is based on the presentation given by Rudolf Klein at the conference on Priority Setting in the Health Service held in March 1993. Papers from a collection of the speakers will be published in a book, "Rationing in Action," this autumn.

Centre for the Analysis of Social Policy, University of Bath, Bath BA2 7AY

Rudolf Klein, director
Priority setting is a complex interaction of multiple decisions at various levels in the organisation and constrained by history. There is no self evident set of ethical principles or analytical tools to determine what decisions we should take at various levels, nor is there an obvious or easy way to resolve the clash of claims on resources. To make priority setting more "rational" we should concentrate on the processes and structure of decision making and the relation of macro and micro decisions. The debate should promote reasoned, informed, and open argument, draw on a variety of perspectives, and involve a plurality of interests. The aim must be to build up, over time, the capacity to engage in continuous, collective argument.

My starting point is the all pervasive nature of priority setting in all health care systems. Decisions about how to allocate resources-what we call, if we want to raise the emotional level of the debate, rationing - take place at all levels of the organisational hierarchy and the delivery system. Everyone in any health care system is (to exaggerate only a little) taking decisions about how best to prioritise resources all the time. The process starts from the moment I enter my general practitioner's surgery. The receptionist takes a decision, when I ask for an appointment, about how urgent my case is: what Roy Parker called, in a seminal article published 25 years ago, rationing by deterrence or delay. ${ }^{1}$ When I eventually get to see my doctor, he or she will decide whether to give me five minutes or ten. Next will come a decision about whether or not to refer me to hospital (unless I shortcircuit the whole process by having a heart attack). Then I may or may not be put on a waiting list, and eventually-if I survive rationing by delay and depending on the priority rating I get-I may get to be treated in hospital. While I am there, doctors will take decisions about just what resources to throw at me-rationing by dilution, in Parker's terminology-and just how many tests and investigations to order. Finally, there will be decisions about how long to keep me in hospital: rationing by termination of treatment

Two things need to be noted about this process. Firstly, all the microdecisions about priority setting are constrained by macrodecisions about resource allocation taken at superior levels in the organisational hierarchy: decisions in the cabinet about how much to allocate to the NHS, decisions by the Department of Health about what priority targets to set to health authorities, and finally decisions by purchasers about what services to buy. Secondly, all the microdecisions are taken in terms of "need" as interpreted by the professional providers, notably the medical profession -that is, the perceived level of severity and urgency. Need, we have to recognise, is both an imprecise and an elastic concept, variously interpreted by different practitioners ${ }^{2}$ : hence, of course, the frequently observed and much commented on variations in referral and operating rates. ${ }^{3}$

\section{Multiple decisions for allocating resources}

So when we talk about priority setting we are really discussing the complex interaction of multiple decisions, taken at various levels in the organisation, about allocating resources. The secretary of state for health, Mrs Bottomley, could doubtless make the task of priority setting for doctors somewhat easier if she winkled out more funds for the NHS, though it is dangerous to assume that there would be no need for rationing if only Britain spent a higher proportion of the national income on health care. The case of the Netherlands provides a warning on this point: the Netherlands spent $8 \%$ of its gross domestic product on health care in 1990, in comparison to the United Kingdom's $6 \cdot 2 \%{ }^{4}$ yet it is currently debating what should and should not be included in the services provided-witness the publication of the Dunning report. ${ }^{5}$ Conversely, the medical profession could make Mrs Bottomley's life much more pleasant by putting fewer people on the waiting lists (not a self evidently absurd proposition, given that there are no nationally agreed criteria for treatment and considerable evidence of variations in thresholds used by different consultants). To exaggerate only a little, demand for health care is what the medical profession chooses to make it: the pace at which it introduces new technologies, the rate at which it adopts new procedures, and so on.

Moreover, we are talking about decisions constrained by history: the inherited pattern of distribution between different sectors of the NHS and between different specialties. Priority setting is, inescapably, an incremental process. It involves decisions about how to spend the annual budgetary increment or how to react to budget cuts. In theory it may be possible to reallocate existing resources - to start from a clean slate and adopt a strategy of zero based budgeting-but in practice institutional resistance makes it difficult to do so on a large scale or in the short term. The constituency for the status quo tends to be powerful in health care, as in other services. Those who benefit from the existing pattern of service provision, whether as providers or consumers, tend to be concentrated and organised advocates for maintaining it, while those who stand to gain from the reallocation of funds are, by definition, a diffuse and difficult to identify group. The point is well illustrated by an analysis of the 1992-3 purchasing plans carried out at Bath ${ }^{6}$ as part of a larger study of resource allocation policies in the NHS funded by the Nuffield Hospitals Trust. This showed a general reluctance to choose between competing claims on resources, with little evidence of explicit rationing (in the sense of limiting the menu of services offered by the NHS) or of any willingness to make dramatic changes. To the extent that the purchasers were prepared to modify the existing distribution of resources, it was very much at the margins. They tended to pursue a policy of "spreading the money around"-that is, of keeping as many people as possible happy by giving them some funds - even if this meant giving them only token amounts.

There is nothing surprising about such findings. They are very much in line with what would be expected on the basis both of theory and of the NHS's practice over the past 40 years. But it may be possible to draw out some less obvious implications. My starting point in doing this is the contention that there is no self evident set of ethical principles or of analytic 
tools which allows us to determine what sort of decisions we should take at different levels in the organisation. Consider, first, the question of what priority the government should give to health care when considering competing claims on resources. No one has yet come up with a convincing method for determining how much should be spent on the NHS. Much has been made of the famous $2 \%$ formula, the contention that the NHS needs an annual increment of $2 \%$ in its budget to cope with demographic and technological change. But this is based on extrapolating past trends and does not tell us anything about the adequacy or otherwise of the baseline from which the calculations start. Nor do comparisons with other countries help much. If another country spends a higher proportion of the national income on health care it may be because it is providing more health care or because each unit of service produced is more expensive or, come to that, because it is spending too much on ineffective procedures. And some nationsnotably Denmark and Japan-spend much the same proportion as Britain without seemingly perceiving their health care systems to be underfunded and suffering from the kind of periodic crises that have afflicted the NHS since its birth.

\section{Distributing the budget}

Moving, next, to decisions about how to distribute the total budget among services, there is once again no obvious or easy way of resolving the clash of claims on resources.? Quality adjusted life years (QALYs), as even the advocates of this decision making tool concede, are at best aids to decision making, providing an input of information. They are beset by methodological problems about the valuation of different states of health, by lack of data about outcomes, and by the problem of patient heterogeneity (the fact that the benefits of any given procedure may vary greatly among patients). Public opinion surveys are extraordinarily sensitive to the way in which questions are put and raise worrying issues about what weight should be put to answers given without any contextual information. Moreover, "the public" is a complex notion. As consumers of health care we may well have different priorities from those we have as citizens, just as there may well be differences between the consumers and the providers. ${ }^{8}$ We could say, of course, that priority should always be given to procedures that are demonstrably effective over those that are not. It is difficult to disagree with this proposition, but I am not sure how

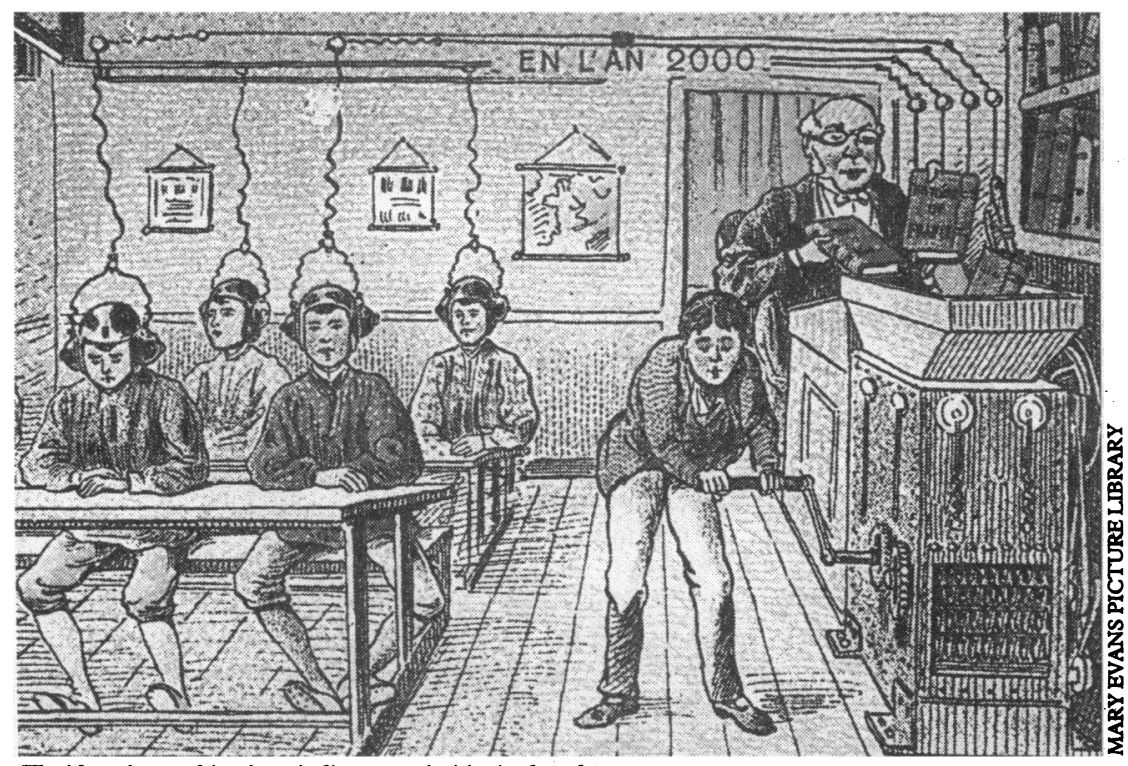

The idea of a machine for grinding out priorities is absurd far this gets us given the extent of our ignorance about effectiveness. Similarly, we could say that priority should follow need. But, again, how far does this get us, given the ambiguity of the concept? Moreover, if it is difficult to devise acceptable principles for prioritising medical interventions (the curing or repair function of the NHS), the problem is compounded when we address questions about allocating resources to the caring function of any health care system and the management of chronic conditions.

\section{Making priority setting more "national"}

All this may suggest that the argument is moving towards the despairing conclusion that there is no "rational" way of determining priorities: that, like it or not, we are still left with priorities emerging from pluralistic bargaining between different lobbies, modified by shifting political judgments made in the light of changing pressures. To an extent, indeed, that is my conclusion. But I would like to argue, firstly, that such a conclusion is not as negative as so often assumed and, secondly, that there is scope for making the process of priority setting more "rational."

My first contention is that, given the plurality of often conflicting values that can be brought to any discussion of priorities in health care, it is positively undesirable (as well as foolish) to search for some set of principles or techniques that will make our decisions for us: the idea of a machine for grinding out priorities is absurd. What is so often wrong about pluralistic bargaining is that it is not pluralistic enough: that discussion is dominated by some voices (notably those of the medical profession). Similarly, pluralistic bargaining often tends to confuse arguments based on interests with those based on values (although most of us have a highly developed capacity for translating our self interest into the high flown language of values).

From this follows my second point, which is that if we are concerned to make priority setting somehow more "rational" (a dangerous word, anyway), we should concentrate on the process of decision making. Rationality, from this perspective, lies in creating a situation in which there is open dialogue, in which opportunities for taking part in debate are widely distributed, in which arguments can be tested against evidence and the conflicts between different values or preferences can be explored. It is a concept of rationality which goes back to Aristotle and which puts the emphasis on finding "good reasons" to justify decisions. And it is an approach which, I would argue, leads us out of the dead end of searching for some overarching formula for determining priorities by directing our attention to the structure of decision making.

\section{The structure of decision making}

Taking this approach, the question then becomes: how far does the present structure of decision making allow rational argument (in the sense of reasoned and open discussion) about priorities? So we might start at the top of the decision making hierarchy and ask how the secretary of state and her department reach - and can justify-their priorities. We might further ask what criteria and evidence are used to come to such decisions about the allocation of resources: the balance between political expediency, cost-benefit considerations, and other factors. Next we might probe the extent to which other actors-such as the House of Commons health committee-can challenge and test the way in which the department formulates its policies. Are there enough opportunities for putting the department on the rack of cross examination and exploring alternative options? 
Moving down one step in the organisational hierarchy, we might ask much the same sort of questions about purchasers. What assumptions, evidence, and criteria shape the policies about priorities? Which interests are represented in the decision making arena and, equally important, who is excluded? If public opinion surveys do not necessarily make much of a contribution to reasoned argument, although they may contribute some raw material, are there other ways in which purchasers test out their own plans and offer an opportunity to others to challenge their arguments and presumptions? Is the process of priority setting transparent enough?

Similarly, moving to the micro level of decision making, we can ask about the processes by which clinicians prioritise between the competing claims on resources and on their time. What criteria do they use in determining entry to, and progress up, waiting lists? What are their definitions of "need," and what weight do they give to different considerations-such as the age of the patient, the costs and effectiveness of different types of treatment, or the social implications of delay? And, again, we might ask to what extent such decisions are open to challenge: whether, for example, medical audit is an adequate instrument for testing different clinical policies and priorities. Should clinicians have to justify their judgments about prioritiesabout whom to treat, at what level of intensity-to a wider audience?

Finally, we should be concerned about the relationship between macro and micro decisions: in particular the feedback between the different levels in the organisational hierarchy. It is not self evident that at present there is adequate information about how broad macrodecisions about priorities, taken at the top of the hierarchy, translate into clinical decisions at the bottom about who should be treated and how. Again, waiting lists provide a classic example: lacking any evidence about the criteria used for giving priority to different patients, we simply do not know whether lengthening queues mean that the threshold of admission has been lowered or whether they imply that access is being delayed or denied to patients who previously would have been treated. Yet, in the absence of such information, how can there be rational argument about the government's priorities?

\section{The structure of the debate}

My argument then, to sum up, is that there is no technological fix, scientific method, or method of philosophic inquiry for determining priorities. Of course, the three Es-economists, ethicists, and epidemiologists - all have valuable insights to contribute to the debate about resource allocation and rationing, though none of them can resolve our dilemmas for us. But what really matters is how that debate is structured: how far it promotes reasoned, informed, and open argument, drawing on a variety of perspectives and involving a plurality of interests. The debate about priorities will never be finally resolved. Nor should we expect any final resolution. As medical technology, the economic and demographic environment, and social attitudes change, so almost certainly will our priorities. And we have to recognise that much of medicine is about the management of uncertainty, where research may roll back the frontiers of ignorance but is never likely to eliminate totally the need for clinical discretion and the use of judgment in interpreting the evidence about efficacy and outcomes.

Our aim must therefore be to build up, over time, our capacity to engage in continuous, collective argument. This means, in turn, devising institutions that encourage, rather than discourage, challenge, allow the implications of pursuing different priorities to be tested out, and provide the information required for reasoned debate. In short, we should be at least as much concerned with the structure of our institutions, and the way in which they work, as with the development of techniques. The politics of priority setting (in the widest sense) matter as much as the methodologies used.

This is very much a recipe for the long haul, but it is one that acknowledges the multidimensional complexity of priority setting, for it is precisely this complexity which does not allow any easy or quick solutions and which forces us to accept (however reluctantly) that this is a voyage of discovery where we will never reach a final destination. To put it another way, this is an argument that will never be finally settled, but in which we can try at least to ensure that it is conducted with due concern about openness, the appropriate use of evidence, and attention to what counts as good currency in the debate.

This paper draws on research on priority setting in the NHS funded by the Nuffield Provincial Hospitals Trust.

1 Parker R. Social administration and scarcity. In: Butterworth E, Holman R, eds. Social welfare in modern Britain. London: Fontana, 1975:204-12. 2 Cooper MH. Rationing health care. London: Croom Helm, 1975.

3 Ham C, ed. Health care variations. London: King's Fund Institute, 1988. 4 Organisation for Economic Cooperation and Development. The reform of health care. Paris: OECD, 1992.

5 Report of the government committee on choices in health care. Risjwijk: Ministry of Welfare, Health, and Cultural Affairs, 1992. (A J Dunning, chairman.) 6 Klein R, Redmayne S. Patterns of priorities. Birmingham: National Association of Health Authorities and Trusts, 1992.

7 Hunter D. Rationing dilemmas in health care. Birmingham: National Association of Health Authorities and Trusts, 1993.

8 Groves T. Public disagrees with professionals over NHS rationing. BMF 1993;306:673.

9 Beiner R. Political judgment. Chicago: University of Chicago Press, 1983.

\section{ANY QUESTIONS}

\section{Should children with cold sores be excluded from nurseries?}

Day care centres and nurseries are risky places for infections, and infections with herpes simplex virus are no exception. Epidemics of herpetic stomatitis in nurseries have been known for over 30 years. ${ }^{1}$ It used to be thought that most primary infections with herpes simplex virus were asymptomatic and that stomatitis affected only $5-10 \%$. A careful study of 90 children aged 0 to 37 months in day care, however, found that $\mathbf{5 5}$ of them had primary infection with herpes simplex virus over two years and 51 of these had typical herpetic gingivostomatitis. ${ }^{2}$ Outbreaks occurred once a year.

Cold sores, however, represent reactivation of herpes simplex virus, and viral shedding is considerably less than in primary infection. What is more, shedding of herpes simplex virus often occurs from the oropharynx of asymptomatic seropositive children. In a children's home children without visible lesions were found to shed herpes simplex virus for up to five months every few months. ${ }^{3}$

It is clearly illogical to exclude children with cold sores from nurseries, and possibly even those with primary gingivostomatitis. Emphasis on handwashing, to prevent transfer of infected secretions, is more appropriate.DAVID ISAACS, head, department of immunology and infectious diseases, Children's Hospital, Sydney

1 Hale BD, Rendtorff RC, Walker LC, Roberts AN. Epidemic herpetic stomatitis in an orphanage nursery. FAMA 1963;183:1068-72.

2 Kuzushima K, Kimura H, Kino Y, Kido S, Hanada N, Shibata M, et al. Clinical manifestations of primary herpes simplex virus type 1 infection in a closed community. Pediatrics 1991;87:152-8.

3 Cesario TC, Poland ID, Wulff H, Chin TDY, Wenner H. Six years' experience with herpes simplex virus in a children's home. Am $f$ Epidemiol 1969;90:416-22. 